\title{
Further inquiry into the interaction between the winter North Pacific storm track and the East Asian trough
}

\author{
Minghao Yang ${ }^{1}$ (D) Chongyin $\mathrm{Li}^{1,2} \cdot$ Yanke $\operatorname{Tan}^{3} \cdot \mathrm{Xin}_{\mathrm{Li}^{1}} \cdot \mathrm{Xiong}_{\mathrm{Chen}}{ }^{1} \cdot$ Peilong $\mathrm{Yu}^{1}$
}

Received: 19 November 2019 / Accepted: 29 April 2020 / Published online: 14 May 2020

(c) The Author(s) 2020

\begin{abstract}
Based on the daily ERA-Interim reanalysis, interactions between the winter North Pacific storm track (WNPST) and the East Asian trough (EAT) on the interannual scale are further explored from the perspective of energy conversion and the simplified quasi-geostrophic potential vorticity equation. There is a prominent out-of-phase relationship between the EAT and WNPST on the interannual scale. It is baroclinic energy conversion rather than barotropic energy conversion that is the main physical process that the EAT affects the WNPST. When the EAT is intensified, the energy conversion from mean available potential energy to eddy available potential energy decreases; further, the energy conversion from eddy available potential energy to eddy kinetic energy is attenuated, which leads directly to remarkable weakening in the strength of the WNPST in its peak area and the region west of the date line. In addition, when the WNPST is enhanced, the WNPST dynamic forcing contributes to lowering the geopotential height near the EAT and thus profits to recover the strength of the EAT, while the thermal forcing of WNPST is opposite. However, their joint effect is still to strengthen the EAT, indicating that the impact of WNPST dynamic forcing on the EAT is stronger than that of thermal forcing. The interaction between the WNPST and EAT may be a way for the WNPST to maintain itself.
\end{abstract}

Keywords East Asian trough · Winter North Pacific storm track · Energy conversion · Transient eddy forcing

\section{Introduction}

The East Asian trough (EAT), located off the east coast of the Eurasian continent, is a large-scale topographic wave formed by the thermal contrast between cold land and warm sea and the dynamic effect of the Qinghai-Tibet Plateau topography on the east coast of Eurasia (Held et al. 2002). It is also known as a quasi-stationary trough over the western

Minghao Yang

minghaoyoung@126.com

$\triangle$ Chongyin Li

lcy@lasg.iap.ac.cn

1 College of Meteorology and Oceanography, National University of Defense Technology, Nanjing 211101, China

2 State Key Laboratory of Numerical Modeling for Atmospheric Sciences and Geophysical Fluid Dynamics (LASG), Institute of Atmospheric Physics, Chinese Academy of Sciences, Beijing 100029, China

3 Department of Atmospheric and Oceanic Sciences \& Institute of Atmospheric Sciences, Fudan University, Shanghai 200433, China
Pacific Ocean in mid-latitudes (Leung et al. 2017). As the main component of the winter atmospheric circulation in the Northern Hemisphere, it has well-distinct seasonal, interannual and interdecadal variations (Chen et al. 2005; Huang et al. 2012; Lee et al. 2013; Song et al. 2016), which manipulates not only the winter monsoon activity and the climatology in East Asia but also the extratropic circulation structure of the Northern Hemisphere and even the climate variations in the Euro-Mediterranean region (Yang et al. 2002; Wu et al. 2011; Huang et al. 2013; Ding et al. 2014; Leung et al. 2017; Feng et al. 2018; Sen et al. 2019; Bozkurt et al. 2019). As one of the most energetic regions of synoptic-scale disturbance in the Northern Hemisphere (Blackmon 1976; Chang et al. 2002), the winter North Pacific storm track (WNPST) is located downstream of the EAT, acts as an important bridge in the interactions between the tropics and the middle-high latitudes through heat, water and momentum transport (Chang and Fu 2002; Luo et al. 2011), and has a significant impact on the maintenance of atmospheric circulation and climate change in East Asia (Jin 2010; Kug et al. 2010; Lee et al. 2012). 
The main modes of storm track variations are related to the teleconnection pattern of low-frequency circulation in the Northern Hemisphere (Lau 1988; Ren et al. 2008). The EAT and WNPST are geographically adjacent. The EAT guides cold and dry air to move southward and encounter the warm air in the mid-latitudes over the North Pacific, resulting in the existence of a steep meridional temperature gradient over the near-surface, accompanied by robust atmospheric baroclinicity (Lau and Lau 1984), which is conducive to the development and movement of synoptic-scale transient eddies (Nakamura et al. 2002). Ren et al. (2007) well documented that the first and second leading modes of the WNPST are coupled with the geopotential height at $500 \mathrm{hPa}$ over the North Pacific. Based on the East Asian winter monsoon (EAWM) index (Jhun and Lee 2004) represented by the $300 \mathrm{hPa}$ area-averaged zonal wind, Lee et al. (2010) and Zhang et al. (2014) emphasized the role of local baroclinicity when studying the impact of the EAWM on the WNPST. In addition, Harnik and Chang (2004) stressed the influences of the subtropical Pacific jet width on baroclinic waves using the quasi-geostrophic model and the primitive equation model.

On the other hand, many studies have shown that there is a symbiotic relationship between large-scale time-mean flow anomalies and transient eddy anomalies in the Northern Hemisphere. Robertson and Metz (1989) argued that synoptic-scale transient eddies and their variations play an important role in maintaining the dynamics of time-mean flow and atmospheric low-frequency variations. The timemean flow anomalies are subject to the influence of continuous feedback from transient eddies, especially in middle and high latitudes (Lau 1988; Lau and Nath 1991). Leung and Zhou (2016) well documented that transient eddies contribute to the strength variations in the EAT on the seasonal, intraseasonal, and synoptic time scales. In addition, Song et al. (2016) investigated the impact of synoptic-scale transient eddies on intraseasonal variations in the strength of the EAT through the three-dimensional quasi-geostrophic potential vorticity equation.

When studying the important modulation role that the EAWM plays in the WNPST on an interannual scale, the local atmospheric baroclinicity (Lee et al. 2010; Zhang et al. 2014) and the narrowing subtropical Pacific jet (Harnik and Chang 2004) have been concerned by predecessors. In addition, most of the studies focus mainly on the linkage between the EAT and transient eddies on the intraseasonal timescale (Leung and Zhou 2016; Song et al. 2016), whereas the interactions between the EAT and WNPST on the interannual scale have not been narrowly investigated. What is the relationship between the EAT and WNPST on the interannual scale and how do they interact with each other? Although it is tough to clarify the causal relationship between the EAWM and WNPST and explaining the relationship between them may not necessarily be straightforward (Lee et al. 2010; Nakamura et al. 2002), to answer these two questions and increase the understanding of midlatitude atmospheric circulation, this article focuses on the impact of the EAT on the WNPST from the perspective of energy conversion within the framework of the linear theory of baroclinic instability and the influence of the WNPST on the EAT in terms of the simplified quasi-geostrophic potential vorticity equation. The remainder of this paper is organized as follows: a brief description of the data and methods is presented in Sect. 2. The relationship between the WNPST and EAT is explored in Sect. 3. The influences of the EAT on the WNPST are addressed in Sect. 4. The impact of the WNPST on the EAT is given in Sect. 5. Finally, conclusions and discussions are provided in Sect. 6.

\section{Data and methods}

Daily atmospheric data used in this research, including winds, air temperature and geopotential heights, are provided by ERA-Interim global atmospheric reanalysis datasets (Dee et al. 2011), with a horizontal resolution of $1.5^{\circ} \times 1.5^{\circ}$ and a time span of $1979-2017$. The data for this time period are more reliable because they incorporate satellite observations (Liu et al. 2014). In this article, winter refers to the time period from December in the current year to January and February in the next year.

The variability of the EAT is measured by defining the East Asian trough index (EATI) as the opposite of the standardized mean geopotential height at $500 \mathrm{hPa}$ in the area of $\left(25^{\circ}-45^{\circ} \mathrm{N}, 110^{\circ}-145^{\circ} \mathrm{E}\right)$, which is the same definition used by Sun and Li (1997) and Miao et al. (2018). The geopotential height field in this selected area reflects the main activity characteristics of and strength variations in the EAT (Wang and He 2012). The EATI can be expressed as:

$\mathrm{EATI}=-\frac{\sum_{i}^{N x} \sum_{j}^{N y} Z_{i j}}{N x \times N y}$

where $N x$ and $N y$ represent the number of grid points in the zonal and meridional directions of the selected rectangle, respectively. $Z_{i j}$ is the standardized geopotential height at each grid point $(i, j)$. In this way, the larger EATI corresponds to the stronger EAT.

The storm track can be characterized by eddy kinetic energy, meridional heat flux, geopotential height, meridional wind speed, sea level pressure and other physical variables (Chang and $\mathrm{Fu}$ 2002). We use the Lanzcos bandpass filter to separate synoptic-scale (2.5-6-day) disturbances from the ERA-Interim daily reanalysis datasets, and the WNPST is represented by the standard deviation of the $500 \mathrm{hPa}$ filtered geopotential height field. 
In addition, to facilitate the study of the interaction between the WNPST and EAT, it is necessary to find an index to reasonably describe the WNPST. This paper adopted the method of Li and Zhu (2010) to define the storm track strength index (STSI). Specifically, the median strength of all grid points in the range of the WNPST climatological mean $\left(25^{\circ}-65^{\circ} \mathrm{N}, 130^{\circ} \mathrm{E}-120^{\circ} \mathrm{W}\right.$ ) (Yang et al. 2018) is selected as the threshold, and the average WNPST strength of all grid points greater than this threshold is recorded as the STSI after standardization, which can be expressed as:

$\mathrm{STSI}=\frac{1}{N} \sum_{1}^{N} \sqrt{Z^{\prime} Z^{\prime}}$

where $N$ is the number of grid points on which the strength exceeds the median WNPST strength of all the grids within the climatological region and $\sqrt{Z^{\prime} Z^{\prime}}$ denotes the WNPST amplitude. The prime in the superscript represents a 2.5-6day filtered synoptic component. Anomalies of a given variable in the present study are generated by removing its climatological mean and long-term linear trend.

(a) 2.5-6 day band-pass $500 \mathrm{hPa} \mathrm{Z}$

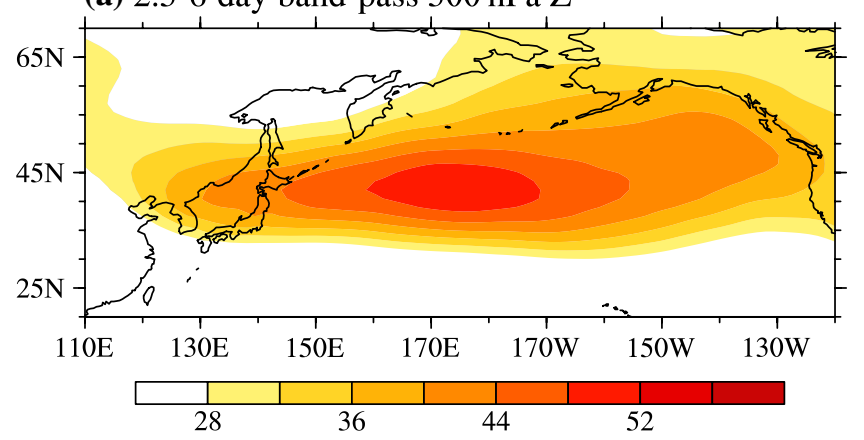

\section{Relationship between WNPST and EAT}

The WNPST is mainly located over the North Pacific to the east of Japan and to the north of the Kuroshio extension (Fig. 1a), with a slight southwest-northeast orientation and a peak area near the dateline. The climatological mean of the EAT in winter is near Japan (Fig. 1b). The EAT lies to the west of the main body of the WNPST, whereas the WNPST is situated slightly downstream of the EAT and modulated by the intensity and steering action of time-mean flow (Lau 1988). It is clear that the EAT and WNPST are closely related geographically.

Figure 1c displays the time series of EATI and STSI in winter from 1979 to 2016. It can be observed that they show an obvious out-phase relationship, with the correlation coefficient as high as -0.72 . If the fast Fourier transform is used to remove interannual (interdecadal) signals, their correlation coefficients are $-0.86(-0.57)$, both of which have a 99\% confidence level, indicating that the negative correlation between EAT and WNPST is present on both interannual and interdecadal scales. If the definition of the STSI is followed, the strength in formula (2) is replaced by longitude and latitude, which are denoted as the zonal position index (ZPI) and meridional position index (MPI), which can be written as $Z P I=\sum_{1}^{N} W N P S T_{\text {lon }} / N$ and $M P I=\sum_{1}^{N} W N P S T_{\text {lat }} / N$,

\section{(b) $500 \mathrm{hPa} \mathrm{Z}$}

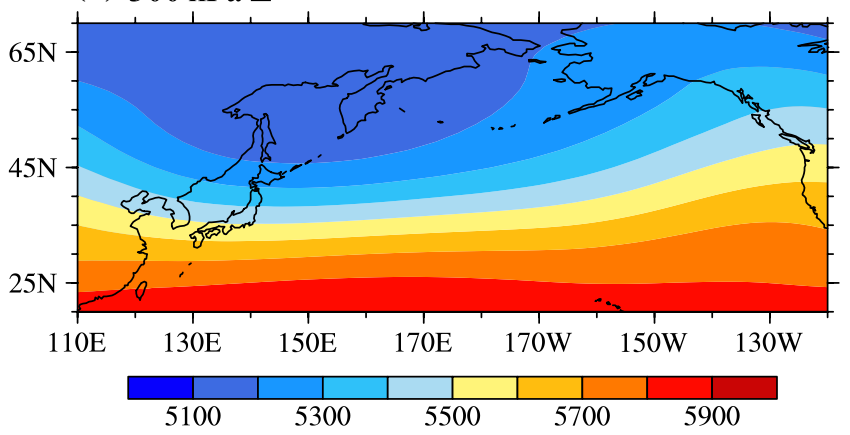

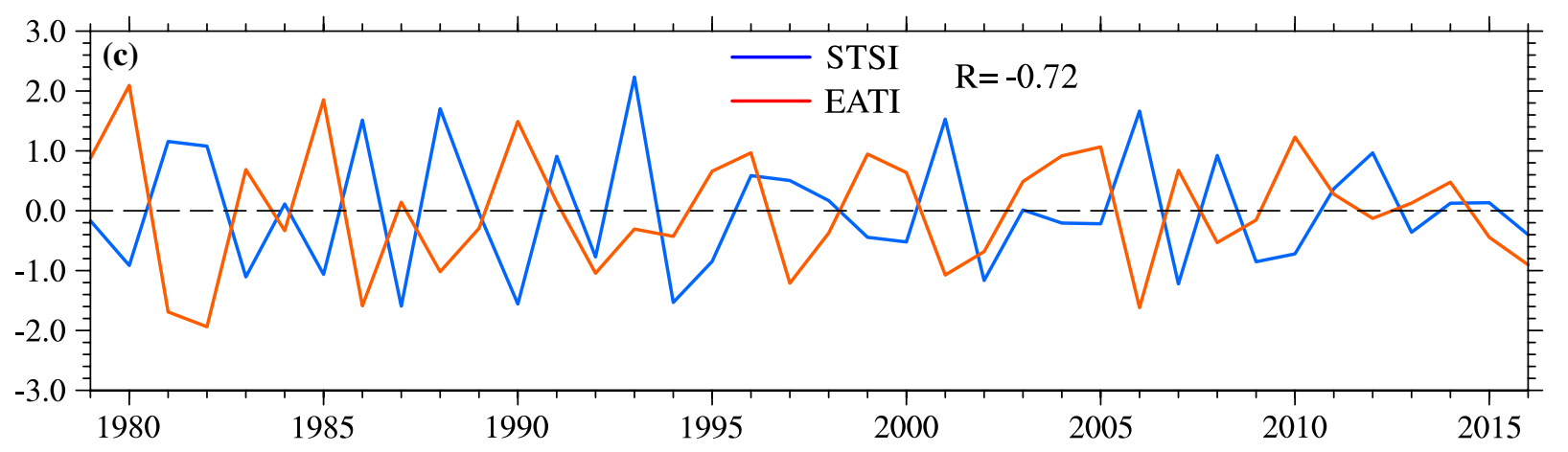

Fig. 1 Spatial pattern (shading) of the climatological a WNPST (unit: m) and b EAT (unit: gpm), and c the monthly time series of (red) EATI and (blue) standardized STSI 
where $W N P S T_{\text {lon }}$ and $W N P S T_{\text {lat }}$ represent the longitude and latitude on the grid point, respectively. However, the correlation coefficients of EATI and ZPI (MPI) are only -0.01 $(-0.11)$, which fail to pass the significance test and imply that there is no significant correlation between the strength of the EAT and the spatial position of the WNPST.

In addition, using different metrics to represent the storm track, Chang et al. (2012) came to a different conclusion about the intensity trend of the North Atlantic storm track during the period 1980-2010. Therefore, considering that the results may vary with the choice of physical variables used to characterize the storm track (Wang et al. 2017), we also use filtered sea level pressure, $850 \mathrm{hPa}$ meridional eddy heat flux and $300 \mathrm{hPa}$ meridional wind velocity for verification. Table 1 shows the correlation coefficients of the EATI

Table 1 The correlation coefficients of the EATI and STSI calculated by diversely characterized WNPST, including the filtered sea level pressure (SLP), standard deviation of geopotential height at $500 \mathrm{hPa}$ (H'500), $850 \mathrm{hPa}$ meridional eddy heat flux (V'T'850) and $300 \mathrm{hPa}$ meridional wind velocity (V'V'300)

\begin{tabular}{llll}
\hline SLP & V'T'850 & H'500 & V'V'300 \\
\hline $0.43^{*}$ & $0.58^{*}$ & $0.72^{*}$ & $0.62^{*}$ \\
\hline
\end{tabular}

The asterisk indicates the $99 \%$ confidence level

(a) Strong EAT, $500 \mathrm{hPa}$ band-pass $\mathrm{Z}$

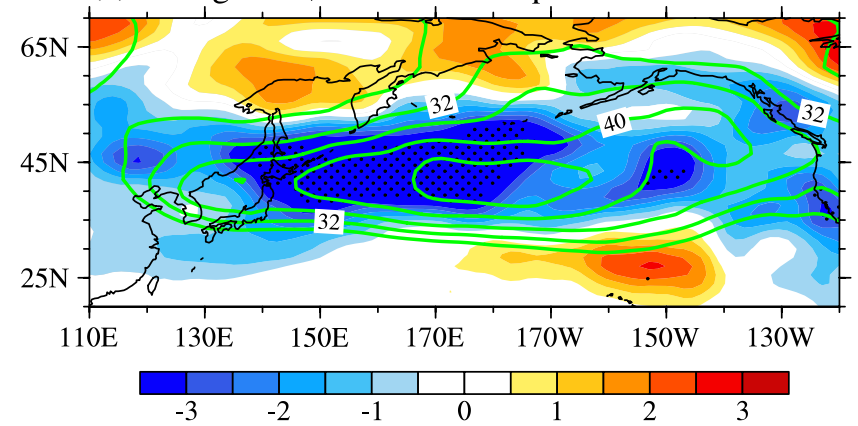

(c) Strong-Weak, $500 \mathrm{hPa}$ band-pass $\mathrm{Z}$

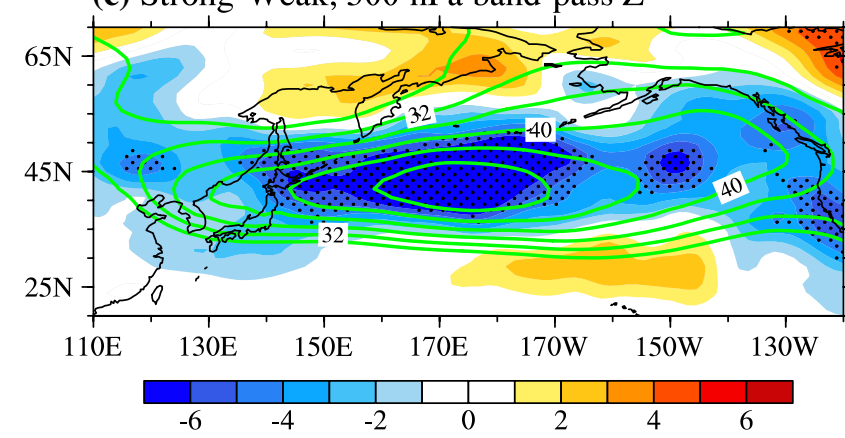

Fig. 2 The composited WNPST (contour, unit: m) in EAT a strong years and $\mathbf{b}$ weak years, and their differences with the WNPST climatological mean (shading, unit: $\mathrm{m}$ ). c The climatology of the WNPST (contour) and the differences in the composited WNPST (shading) and STSI calculated by diversely characterized WNPST. Regardless of how the WNPST is characterized, the correlation coefficient between the EATI and STSI has a 99\% confidence level, which means that a significant negative correlation between the EAT and WNPST does exist and is independent of the representation of the WNPST. Apart from the ERA-Interim reanalysis, we also use the National Centers for Environmental Prediction/National Center for Atmospheric Research (NCEP/NCAR) reanalysis to verify and get a consistent result (figures not shown).

\section{The influence of EAT on WNPST}

Many studies have noted that the anomaly in the WNPST can be reasonably explained from the perspective of how the anomaly in time-mean flow influences it (Lau 1988; Lee et al. 2010). To investigate the impact of the EAT on the WNPST, the standard deviations of synoptic-scale geopotential height are composited to obtain the spatial pattern of the WNPST in the strong and weak EAT years based on the winter EATI. In strong EAT years, the WNPST over East Japan and west of the dateline is significantly weakened compared with its climatology (Fig. 2a), with the strength of the peak area less than $48 \mathrm{~m}$. The

(b) Weak EAT, $500 \mathrm{hPa}$ band-pass Z

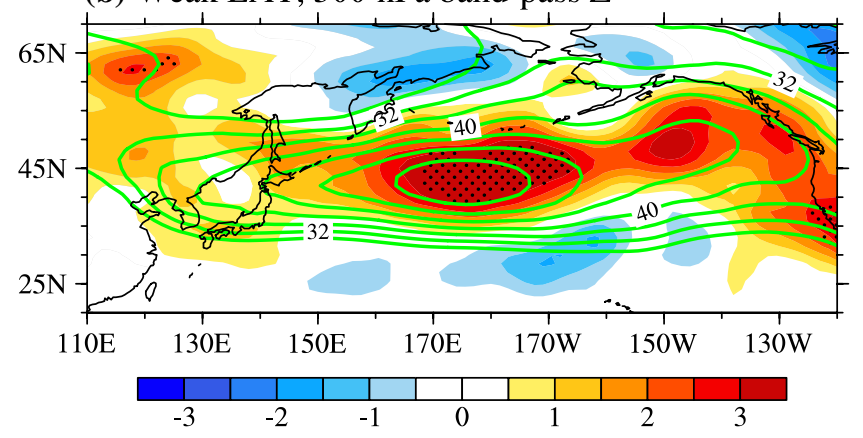

(d) Reg. Coef. on EATI, $500 \mathrm{hPa}$ band-pass Z

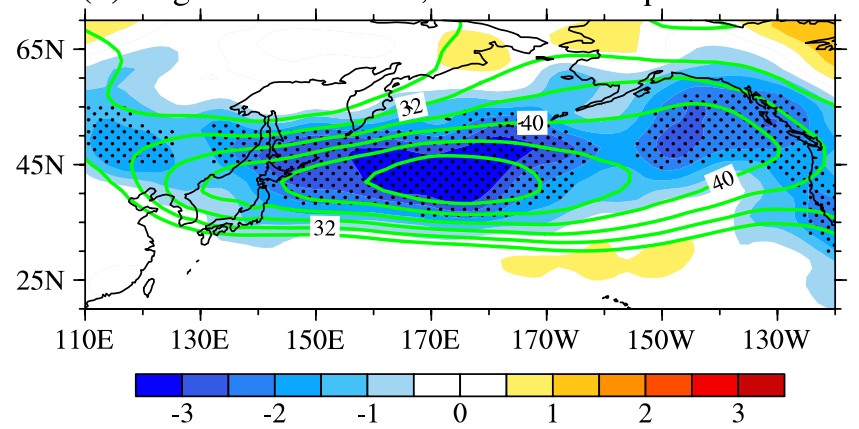

between EAT strong years and weak years. d The climatology of the WNPST (contour) and regression of the WNPST anomalies onto the EATI (shading). The contour interval is $4 \mathrm{~m}$. Dotted areas exceed the 95\% confidence level according to Student's $t$ test 
anomaly center is located to the west of the climatological maximum. However, the amplitudes of the peak area, exceeding $52 \mathrm{~m}$, are significantly enhanced during the weak EAT years (Fig. 2b). Figure 2c exhibits the difference in the WNPST between EAT strong years and weak years, and it can be clearly seen that the strength of the WNPST decreases significantly when the EAT is strong. In addition, the regression analysis in Fig. 2d gives consistent results, which shows that with the enhancement of the EAT, almost the whole WNPST is inhibited, especially the peak region. Since the EAT weakens the WNPST universally rather than regionally, it has little influence on the movement of the WNPST, which explains why the EAT strength is not significantly correlated with changes in the WNPST position.

When the EAT strengthens, the northerly wind carries cold monsoonal flow equatorward from the polar regions and high latitudes and meets the warm air, which would give rise to the intense meridional temperature gradient over the western North Pacific farther to the south (Nakamura et al. 2002). The $500 \mathrm{hPa}$ maximum Eady growth rate (Hoskins and Valdes 1990) decreases significantly north of $40^{\circ} \mathrm{N}$, weakening the atmospheric baroclinicity, which is crucial for North Pacific storm track activity (Ren et al. 2008), thus inhibiting the development of the WNPST and attenuating its intensity (figures not shown). However, the intensified atmospheric baroclinicity induced by the enhanced EAT in the south of $40^{\circ} \mathrm{N}$ have no significant impact on WNPST, which may be attributed to that their amplification effect on WNPST is neutralized by the intensified upper-tropospheric jet which weakens the WNPST (Lee et al. 2010). In addition, apart from the dry mechanism, like atmospheric baroclinicity, moisture effect is also important to the storm track change (Chang et al. 2002; Lee et al. 2011; Ma et al. 2017). Instead of emphasizing that the atmospheric baroclinicity (Lee et al. 2010; Zhang et al. 2014) and the narrowing of the subtropical Pacific jet (Harnik and Chang 2004) play important modulation roles in the development of the WNPST on the interannual scale (Wang et al. 2017), we focus on studying the influence of the EAT on the WNPST from the perspective of energy conversion in the framework of the linear theory of baroclinic instability.

First, we analyze the effect of the barotropic energy conversion (BTEC) from the mean kinetic energy of the time-mean flow to the eddy kinetic energy. The BTEC is linked to the interactions between the stretching deformation and shearing deformation of the time-mean flow and the characteristics of transient eddies, including meridional extension and axis tilt (Hu et al. 2018). The formula for the BTEC can be expressed as (Hoskins et al. 1983; Cai et al. 2007; Lee et al. 2012; Wang et al. 2017):

$$
\begin{aligned}
\mathrm{BTEC} & =\frac{p_{0}}{g} \vec{E} \cdot \vec{D} \\
& =\frac{p_{0}}{g}\left\{\frac{1}{2}\left(\overline{v^{\prime 2}}-\overline{u^{\prime 2}}\right)\left(\frac{\partial \bar{u}}{\partial x}-\frac{\partial \bar{v}}{\partial y}\right)-\overline{u^{\prime} v^{\prime}}\left(\frac{\partial \bar{v}}{\partial x}+\frac{\partial \bar{u}}{\partial y}\right)\right\}
\end{aligned}
$$

wh e r e $\quad \vec{E}=\left(\frac{1}{2}\left(\overline{v^{\prime 2}}-\overline{u^{\prime 2}}\right),-\overline{u^{\prime} v^{\prime}}\right) \quad$ a n d $\vec{D}=\frac{p_{0}}{g}\left(\frac{\partial \bar{u}}{\partial x}-\frac{\partial \bar{v}}{\partial y}, \frac{\partial \bar{v}}{\partial x}+\frac{\partial \bar{u}}{\partial y}\right)$ represent the transient vector and time-mean flow vector, respectively, $p_{0}$ represents $1000 \mathrm{hPa}$, $g$ refers to the gravity acceleration, $u$ and $v$ represent zonal wind and meridional wind, respectively, the prime in the superscript represents transient (2.5-6-day bandpass filtered) components and the overbar represents the climatological mean. If the BTEC is positive, the mean kinetic energy from the basic flow converts to eddy kinetic energy, and vice versa. It can be found from Fig. 3a that although the WNPST has a relatively weak climate state in the strong EAT years, there is a significant positive BTEC anomaly on its south side. However, in the weak EAT years, a slightly negative BTEC anomaly appears on the south side of the enhanced WNPST (Fig. 3b). When the EAT is strong, although some negative BTEC anomalies occur in the western part of the WNPST climatology (Fig. 3c), which is partially responsible for the weakening of the WNPST, the mean kinetic energy from the basic flow converts to eddy kinetic energy in quantities on the southern flank of WNPST climatology (Fig. 3c), which directly favors the development of the WNPST. Thus, it is obvious that the BTEC cannot reasonably explain the weakening effect of the EAT on the WNPST, because positive BTEC anomalies are dominant while the WNPST is still relatively weak compared with its climatology in strong EAT years.

Following Cai et al. (2007), we decompose BTEC into two parts. The first term of BTEC, $\frac{p_{0}}{2 g}\left(\overline{v^{\prime 2}}-\overline{u^{\prime 2}}\right)\left(\frac{\partial \bar{u}}{\partial x}-\frac{\partial \bar{v}}{\partial y}\right)$ obtained from the product of x-components of $\vec{E}$ and $\vec{D}$, is related to the stretching deformation of the basic flow. The second term of BTEC, $-\frac{p_{0}}{g} \overline{u^{\prime} v^{\prime}}\left(\frac{\partial \bar{v}}{\partial x}+\frac{\partial \bar{u}}{\partial y}\right)$ the product of y-components of $\vec{E}$ and $\vec{D}$, is associated with the shearing deformation of the basic flow. The Fig. 4 shows the composite stretching deformation and shearing deformation. We can find that the stretching deformation (Fig. 4a) related to the enhanced EAT contributes to the negative BTEC anomalies located in the western part and positive BTEC anomalies occurring in the eastern part of the climatological WNPST center. In addition, the positive BTEC anomalies in southern flank of WNPST climatological mean can be attributed to the shearing deformation (Fig. 4b) associated with the intensified EAT. The spatial correlation coefficients of stretching deformation and shearing deformation anomalies with BTEC anomalies are both 0.74 , and their root mean square errors with BTEC anomalies are the same, revealing that the stretching deformation anomalies and shearing deformation 
(a) Strong EAT, $500 \mathrm{hPa}$ BTEC

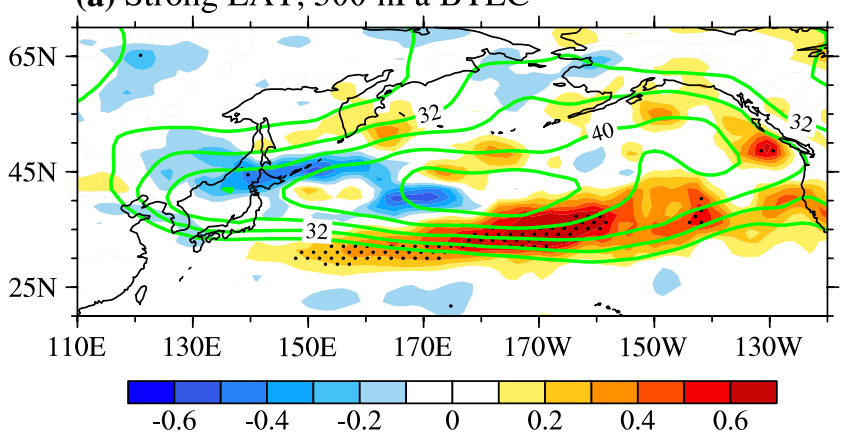

(b) Weak EAT, $500 \mathrm{hPa}$ BTEC

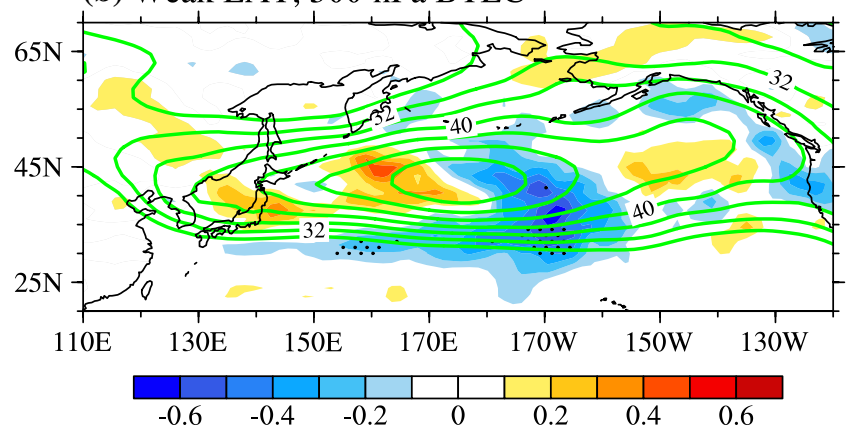

(c) Strong-Weak, 500hPa BTEC

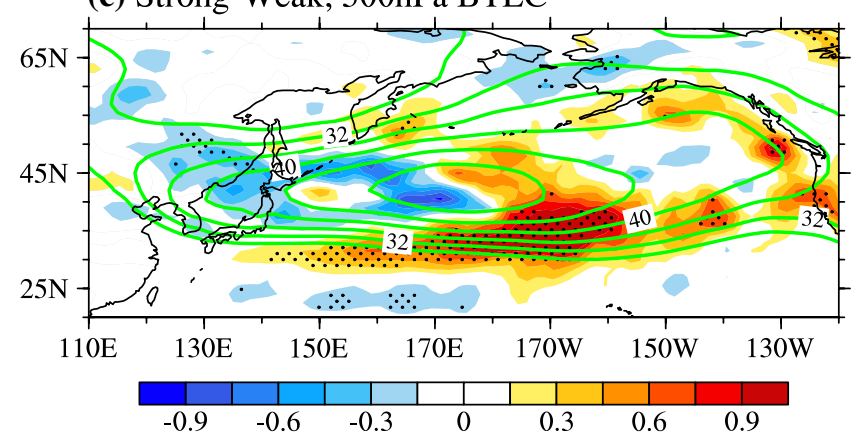

Fig. 3 The differences in the composite BTEC (shading; unit: $\mathrm{W} \mathrm{m}^{-2}$ ) at $500 \mathrm{hPa}$ between a EAT strong years and its climatology, b EAT weak years and its climatology, and $\mathbf{c}$ EAT strong years and weak years. The composite WNPST (contours; unit: m) in EAT a strong and b weak years, and $\mathbf{c}$ the climatological mean of the WNPST. Dotted areas exceed the $95 \%$ confidence level according to Student's $t$ test (a) Strong-Weak, 500hPa stretching deformation

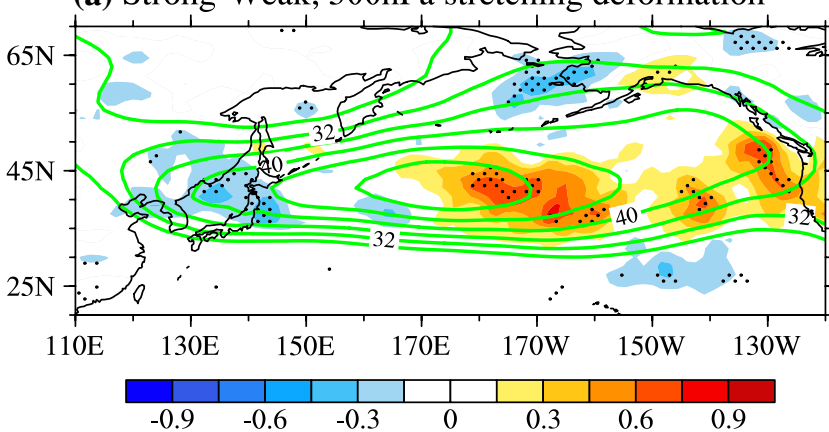

Fig. 4 Maps showing (shading; unit: $\mathrm{W} \mathrm{m}^{-2}$ ) the differences in the composite a stretching deformation and $\mathbf{b}$ shearing deformation associated with BTEC at $500 \mathrm{hPa}$ between EAT strong years and

anomalies are generally equally important to BTEC anomalies.

Except for the BTEC, baroclinic energy conversion (BCEC) is the main energy source for the development of and variations in synoptic-scale transient eddies (Lee et al. 2011; Wang et al. 2017; Yang et al. 2020). The BCEC involves two processes (Cai et al. 2007): the energy conversion from mean available potential energy to eddy available potential energy (BCEC1) and the energy conversion (b) Strong-Weak, 500hPa shearing deformation

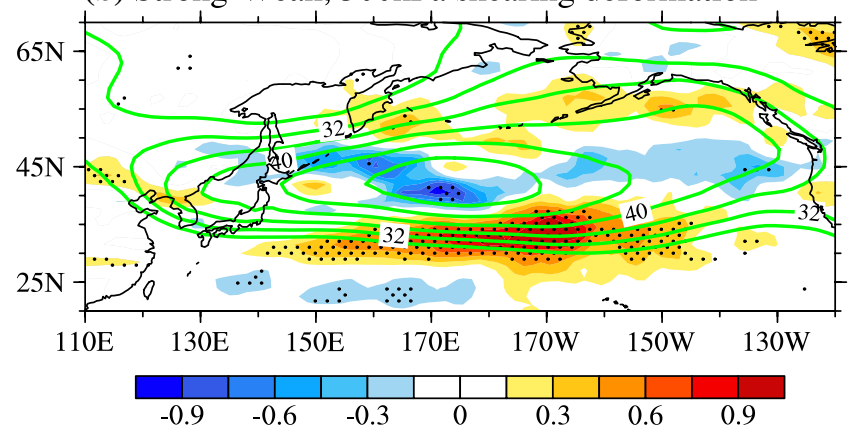

weak years, and (contours; unit: $\mathrm{m}$ ) the climatological mean of the WNPST. Dotted areas exceed the 95\% confidence level according to Student's $t$ test

from eddy available potential energy to eddy kinetic energy (BCEC2). The analysis of the BCEC is based on the following formulas (Dole and Black 1990; Cai et al. 2007; Lee et al. 2012):

$\mathrm{BCEC} 1=C_{2}\left(\overline{u^{\prime} T^{\prime}} \frac{\partial \bar{T}}{\partial x}+\overline{v^{\prime} T^{\prime}} \frac{\partial \bar{T}}{\partial y}\right)$ 
$\mathrm{BCEC} 2=C_{1}\left(\overline{\omega^{\prime} T^{\prime}}\right)$

where $C_{1}=\left(p_{0} / p\right)^{C_{v} / C_{p}}(R / g), C_{2}=C_{1}\left(p_{0} / p\right)^{R / C_{p}}(d p / d \theta)$, $R$ is the gas constant for dry air, $C_{v}$ and $C_{p}$ are the specific heat of dry air at a constant volume and constant pressure, respectively, $\omega$ represents vertical wind and $\theta$ is the potential temperature.

BCEC1 is composed of two parts: one term is the zonal transport of the basic flow zonal temperature gradient and eddy heat; the other term is the meridional transport of the basic flow meridional temperature gradient and eddy heat (Hu et al. 2018). BCEC1 greater than zero indicates that the mean available potential energy from basic flow is converted to eddy available potential energy, and vice versa. Figure 5 exhibits the composite BCEC1 anomalies. Leung et al. (2017) documented that the deeper the EAT is, the stronger the available potential energy. However, the growth of available potential energy does not mean that the conversion to eddy available potential energy, or even eddy kinetic energy, is also enhanced. It can be found that BCEC1 weakened significantly near $40^{\circ} \mathrm{N}$ west of the dateline in the strong EAT years (Fig. 5a), which would not be conducive to the conversion of atmospheric mean available potential energy to eddy available potential energy in this area, thus inhibiting the development of the WNPST. In weak EAT years, significant positive BCEC1 anomalies occurred in the peak area of the WNPST (Fig. 5b). In addition, the pattern of differences in the composite BCEC1 between EAT strong years and weak years (Fig. 5c) corresponds well to the EATinduced WNPST anomalies (Fig. 2c).

The eddy available potential energy needs to be further converted to eddy kinetic energy to directly feed the growth of transient eddies and affect the WNPST. BCEC 2 works by the rising of warm air and the sinking of cold air. If BCEC2 is positive, the eddy available potential energy is converted to eddy kinetic energy. It can be clearly seen from Fig. 6 that the spatial patterns of BCEC2 anomalies are basically in line with those of BCEC1 (Fig. 5) and the WNPST (Fig. 2), indicating that baroclinic energy conversion may be one of the main physical processes by which the EAT affects the WNPST.

\section{The impact of WNPST on EAT}

Nakamura et al. (2002) documented that the transient eddies along the storm track interact with the nearby time-mean flow, but the interaction between the WNPST and EAT is difficult to partition (Lee et al. 2010). In the above section, we studied the influence of the EAT on the WNPST, so the WNPST is supposed to provide manipulation on the EAT. Based on the mid-latitude barotropic quasi-geostrophic framework, we calculate the transient eddy-induced (a) Strong EAT, $500 \mathrm{hPa}$ BCEC1

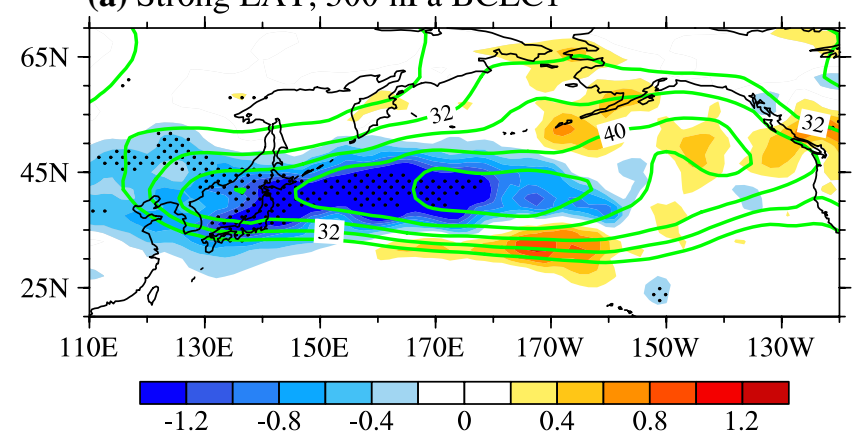

(b) Weak EAT, $500 \mathrm{hPa}$ BCEC1

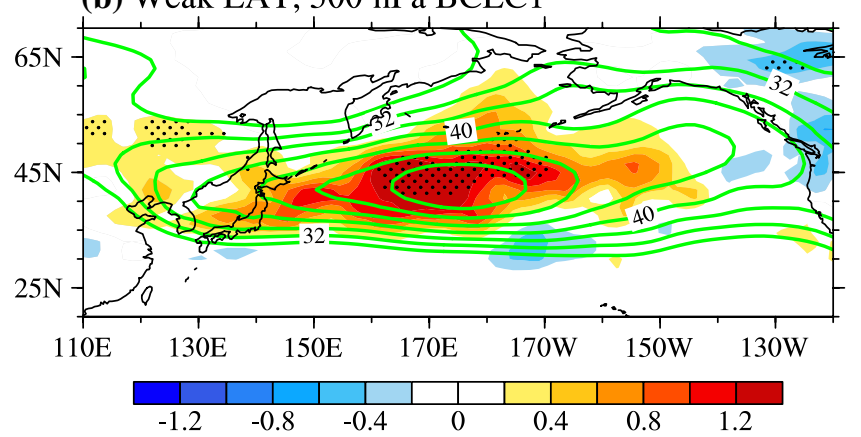

(c) Strong-Weak, $500 \mathrm{hPa}$ BCEC1

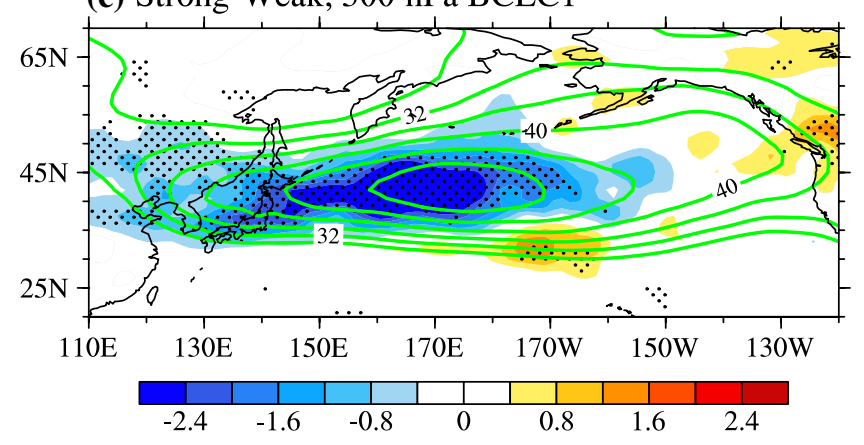

Fig. 5 Same as Fig. 3 but for BCEC1 (unit: $\mathrm{W} \mathrm{m}^{-2}$ ) 
(a) Strong EAT, $500 \mathrm{hPa}$ BCEC2

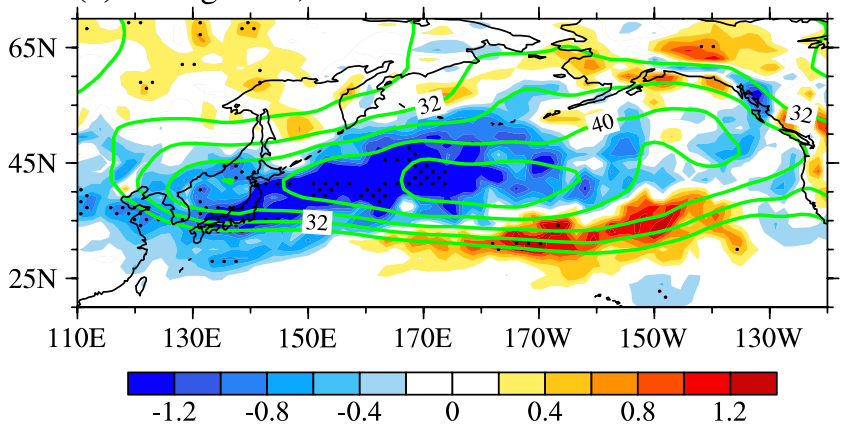

(b) Weak EAT, $500 \mathrm{hPa}$ BCEC2

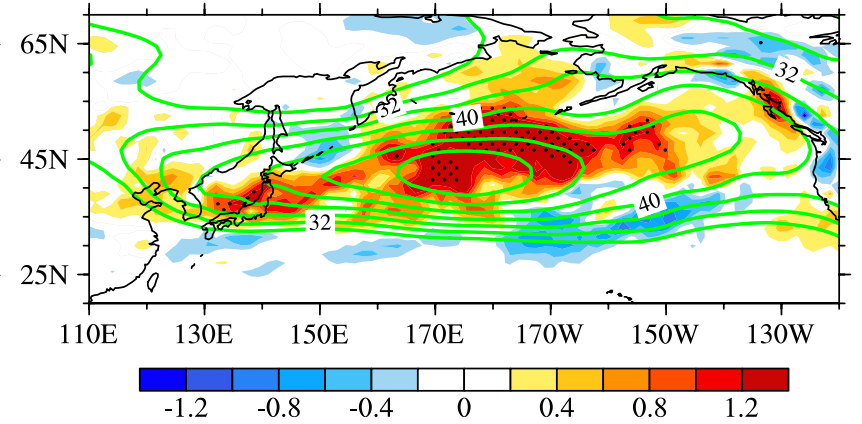

(c) Strong-Weak, $500 \mathrm{hPa}$ BCEC2

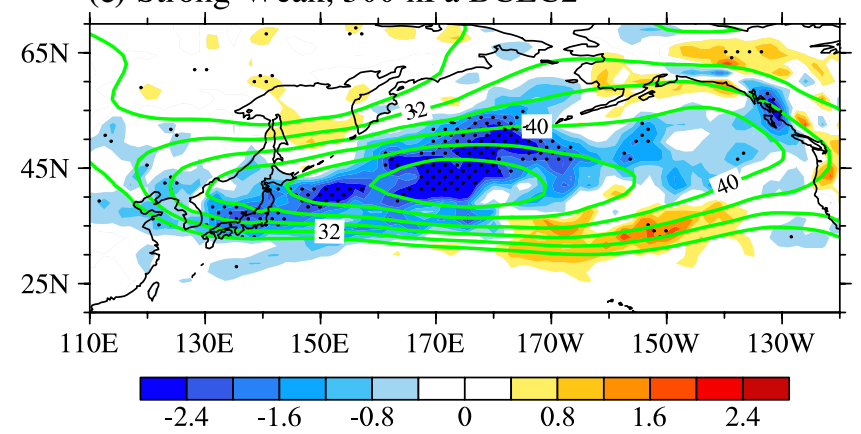

Fig. 6 Same as Fig. 3 but for BCEC2 (unit: $\mathrm{W} \mathrm{m}^{-2}$ )

geopotential height tendency and temperature tendency at $500 \mathrm{hPa}$ (Lau and Holopainen 1984; Nakamura et al. 1997; Cai et al. 2007; Li and Lau 2012), which describes the quantitative aspects of local eddy-basic flow interactions in an explicit manner (Lau and Holopainen 1984) and can be expressed as:

$\frac{\partial Z}{\partial t}=\frac{f}{g} \nabla^{-2}\left\{-\overrightarrow{\nabla \cdot\left(\overrightarrow{V^{\prime}} \zeta^{\prime}\right)}\right\}$

$\frac{\partial T}{\partial t}=-\overline{\nabla \cdot\left(\overrightarrow{V^{\prime}} T^{\prime}\right)}$

where $\nabla^{-2}$ represents the inverse Laplace operator and $\zeta$ denotes the relative vorticity. To facilitate understanding, here, the EAT refers to the $500 \mathrm{hPa}$ geopotential heights in the area $25^{\circ}-50^{\circ} \mathrm{N}, 100^{\circ} \mathrm{E}-180^{\circ}$ (Wang et al. 2009; Song et al. 2016). Figure 7 shows the composite geopotential height tendency anomalies induced by transient eddy dynamic forcing and the geopotential height in WNPST strong and weak years. It can be observed from Fig. 7 that the EAT in WNPST strong (weak) years is less (more) robust than its climatological mean. Markedly negative geopotential height tendency anomalies occur over northeastern Eurasia, the Kamchatka Peninsula and the Aleutian Islands in WNPST strong years (Fig. 7a), which results in a significant reduction in the geopotential height in the mid-high latitudes north of $45^{\circ} \mathrm{N}$, whereas positive anomalies appear $\left(30^{\circ}-40^{\circ} \mathrm{N}, 155^{\circ} \mathrm{E}-180^{\circ}\right)$. Such patterns of geopotential height tendency anomalies would deepen the EAT and reduce its attenuation. Actually, the same is true for the situation in WNPST weak years. We find that substantially positive geopotential height tendency anomalies appear over the Bering Sea in the years with weak WNPST (Fig. 7b), leading to an inhibitory effect on the EAT. In addition, it can be clearly seen from the pattern of differences in geopotential height tendency induced by the WNPST dynamic forcing between the WNPST strong and weak years that when the WNPST is strong, EAT tends to strengthen due to WNPST dynamic forcing-induced geopotential height tendency (Fig. 7c), exhibiting a intensified effect on the EAT.

Next, we analyze the impact of WNPST thermal forcing on the surrounding atmosphere. In WNPST strong years, significantly positive temperature tendency anomalies appear east of the Kamchatka Peninsula, whereas negative anomalies occur over $30^{\circ}-40^{\circ} \mathrm{N}$ and $145^{\circ}-175^{\circ} \mathrm{E}$ (Fig. 8a). This kind of temperature tendency anomaly pattern warms the air over the northwest Pacific Ocean and cools that over the Kuroshio extension, which would damp the zonally westerlies wind and weaken the EAT according to the thermal wind relationship. However, the spatial distribution of temperature tendency anomalies in WNPST weak years is opposite to that in WNPST strong years (Fig. 8b), and it basically fails the significance test. The weakening effect of 
(a) Strong WNPST, $500 \mathrm{hPa} \mathrm{dZ} / \mathrm{dt}$

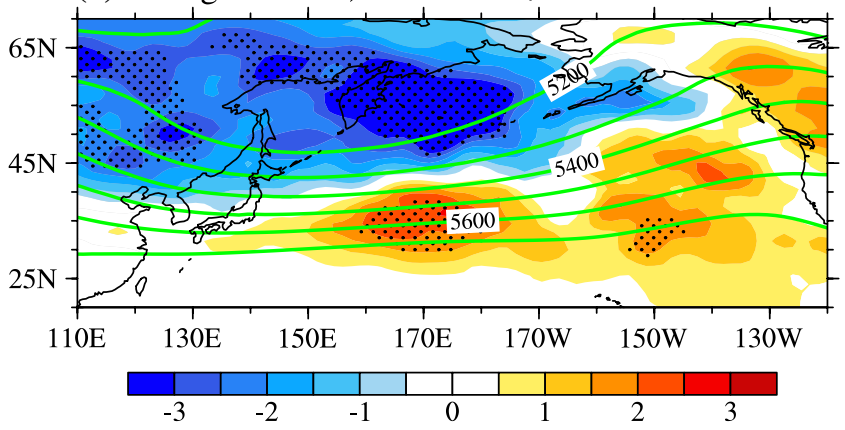

(b) Weak WNPST, $500 \mathrm{hPa}$ dZ/dt

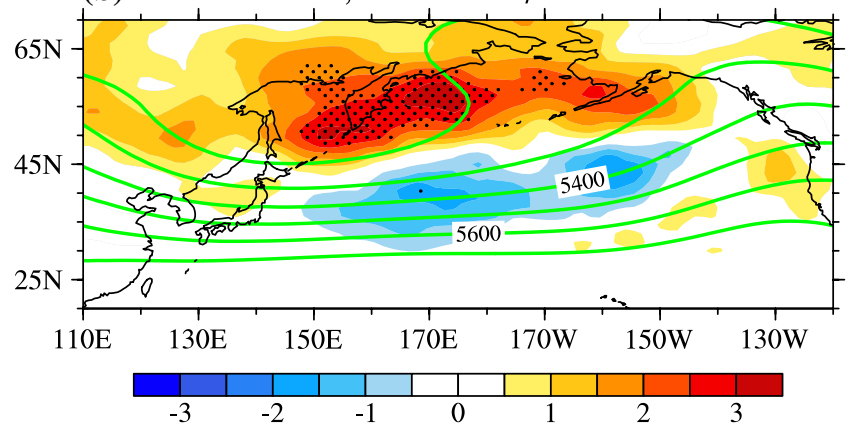

(c) Strong-Weak, $500 \mathrm{hPa} \mathrm{dZ} / \mathrm{dt}$

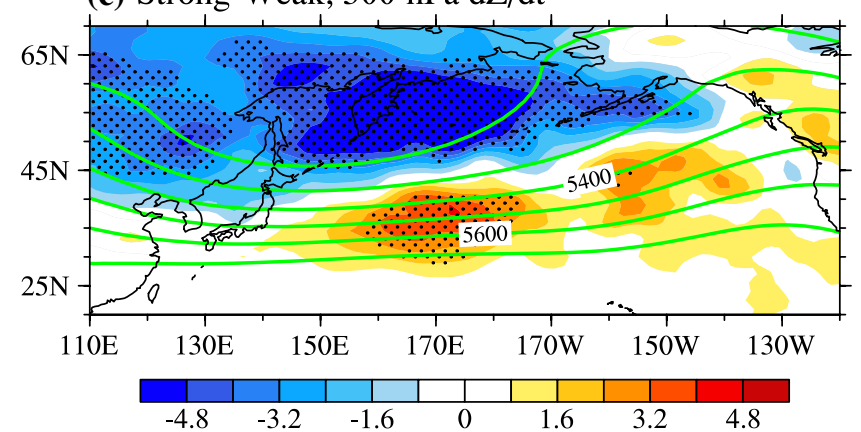

Fig. 7 The differences in composite geopotential height tendency induced by WNPST dynamic forcing (shading; unit: $\mathrm{gpm} \mathrm{day}^{-1}$ ) at $500 \mathrm{hPa}$ between a WNPST strong years and its climatology, b WNPST weak years and its climatology, and c WNPST strong years and weak years. The composite EAT (contours; unit: gpm) in WNPST a strong and $\mathbf{b}$ weak years, and $\mathbf{c}$ the climatological mean of the WNPST. Dotted areas exceed the $95 \%$ confidence level according to Student's $t$ test (a) Strong WNPST, $500 \mathrm{hPa} \mathrm{dT} / \mathrm{dt}$

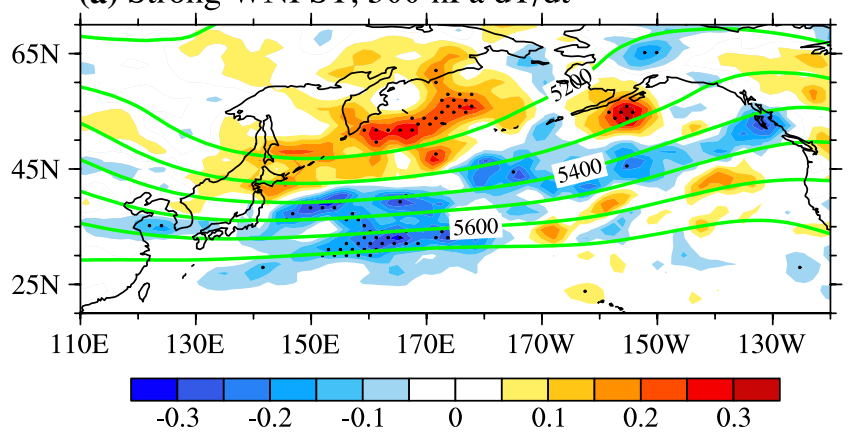

(b) Weak WNPST, $500 \mathrm{hPa}$ dT/dt

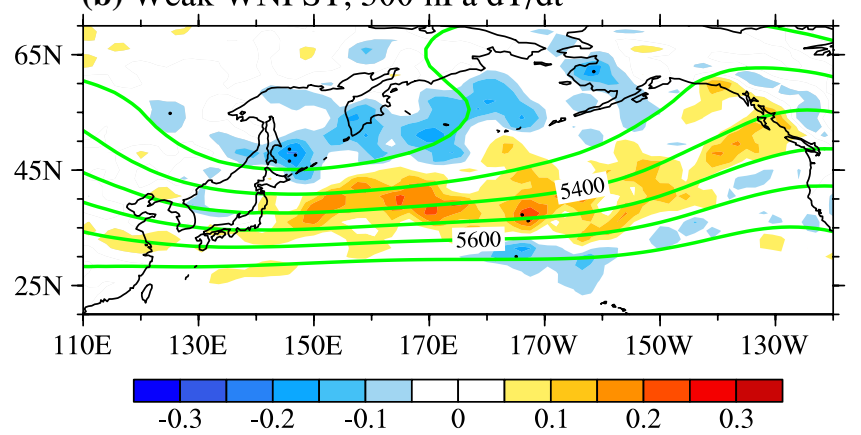

(c) Strong-Weak, $500 \mathrm{hPa} \mathrm{dT/dt}$

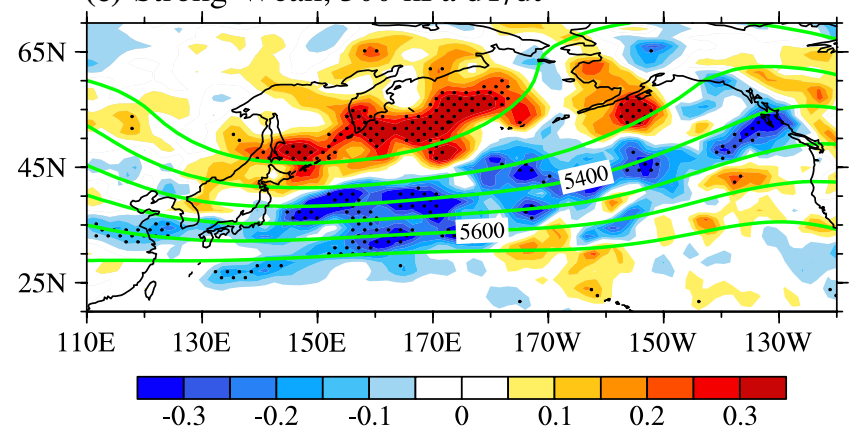

Fig. 8 Same as Fig. 7 but for temperature tendency induced by WNPST thermal forcing (unit: $\mathrm{K} \mathrm{day}^{-1}$ ) 
temperature tendency anomalies induced by WNPST thermal forcing on the EAT for contrasting WNPST strengths can be seen more distinctly in Fig. 8c; when the WNPST is strong, the EAT abates due to WNPST thermal forcing.

It is obvious that geopotential height tendency anomalies and temperature tendency anomalies have opposite effects on the EAT. In other words, the dynamic forcing and thermal forcing by the WNPST manipulate the EAT in opposite ways. It seems difficult to determine the final results of the impact of WNPST on the EAT. In fact, this is not the case. In light of Lau and Holopainen (1984), the temperature tendency and geopotential height tendency can be transformed into each other through the hydrostatic relationship. Specifically, the geopotential height tendency is determined from temperature tendency by setting $\frac{\partial T}{\partial t}=-\frac{p}{R} \frac{\partial}{\partial p}\left(\frac{\partial Z}{\partial t}\right)$. Figure 9 shows the geopotential height tendencies induced by both WNPST dynamic forcing and thermal forcing. In the WNPST strong (weak) years, the anomalies in geopotential height tendencies are almost negative (positive) and not significant compared to their climatological means. However, it can be found from Fig. 9c that the joint contribution of WNPST dynamic forcing and thermal forcing to geopotential height tendency leads to the reduction of geopotential height over East Asia and the North Pacific. Although there are some positive tendencies related to WNPST occurring in the EAT area, few of them pass the significant test. The

(a) Strong WNPST, $500 \mathrm{hPa} \mathrm{dZ/dt}$

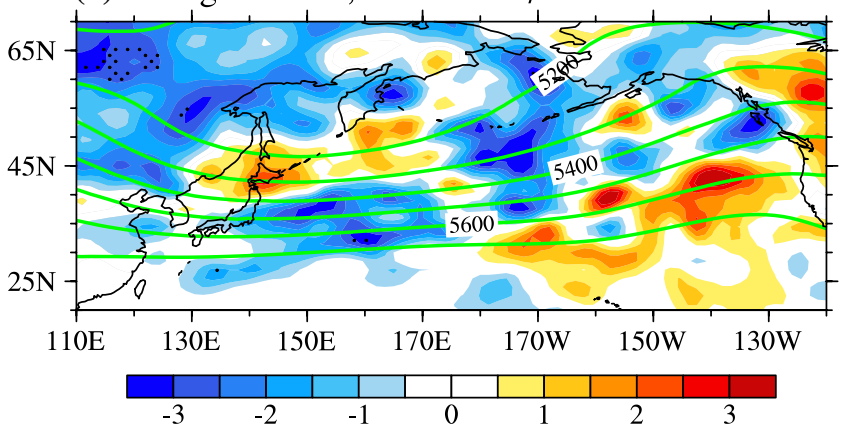

box-averaged geopotential height tendencies over the EAT area $25^{\circ}-50^{\circ} \mathrm{N}, 100^{\circ} \mathrm{E}-180^{\circ}$ is $-1.19 \mathrm{gpm} /$ day, thus deepening and strengthening EAT when the WNPST is strong. That is, the WNPST dynamic forcing has a stronger manipulation on the EAT than its thermal forcing. When the WNPST is intensified, geopotential height tendencies induced by WNPST intensify the strength of the EAT; then, the strengthened EAT in turn weakens the WNPST, and vice versa. It should be emphasized that the features of EAT and WNPST as well as their interaction revealed in the present study are coinstantaneous. It is difficult to identify their causal relationship on the interannual scale.

\section{Conclusion and discussion}

Based on the daily ERA-Interim reanalysis data spanning 1979 to 2010 and the standard deviation of geopotential height at $500 \mathrm{hPa}$ to represent the WNPST, this article investigates the influences of the EAT on the WNPST from the perspective of energy conversion and the impact of the WNPST on the EAT through the simplified quasi-geostrophic potential vorticity equation to further analyze the interaction between the EAT and WNPST on the interannual scale. The main conclusions are as follows:

There is a significant negative correlation between the EAT and WNPST on the interannual scale. When the EAT

(c) Strong-Weak, $500 \mathrm{hPa} \mathrm{dZ/dt}$

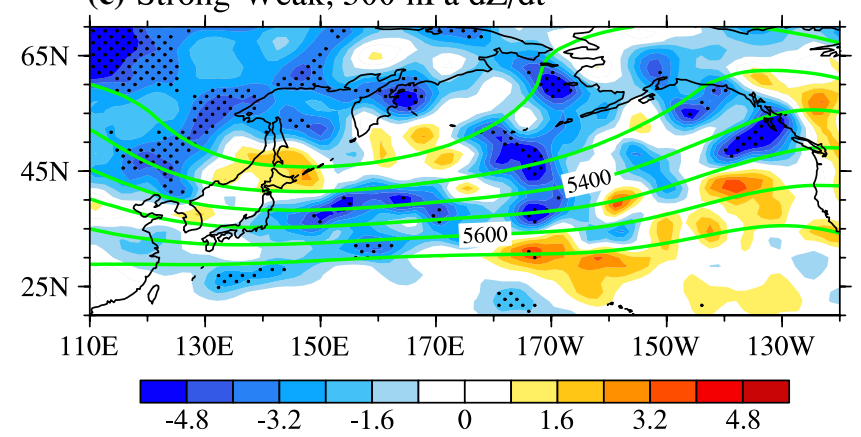

Fig. 9 Same as Fig. 7 but for the joint contribution of WNPST dynamic forcing and thermal forcing to geopotential height tendency (unit: gpm day ${ }^{-1}$ ) 
is strong, the WNPST is prominently weakened relative to its climatological mean on the whole. Instead of barotropic energy conversion, baroclinic energy conversion is the main physical process by which the EAT affects the WNPST. When the EAT is intensified, the energy conversion from mean available potential energy to eddy available potential energy is lessened; further, the energy conversion from eddy available potential energy to eddy kinetic energy is attenuated, which directly leads to remarkable weakening in the strength of the WNPST in its peak area and the region west of the dateline.

When the WNPST is enhanced, the dynamic forcing of the WNPST contributes to reducing the geopotential height near the EAT and thus profits provide a favorable condition for recovering the strength of the EAT. The thermal forcing tends to destroy the atmospheric baroclinicity by augmenting the poleward heat flux transport, which is not only attenuate the development and enhancement of the WNPST but also weakens the strength of the EAT according to the thermal wind relationship. By combining the dynamic forcing and thermal forcing of WNPST through the hydrostatic relationship, it is found that their joint effect is still to reduce the geopotential height over East Asia and strengthen the EAT, which is consistent with the effect of dynamic forcing, indicating that the feedback effect of WNPST dynamic forcing on the EAT is stronger than that of thermal forcing.

Previous studies have examined the influence of the EAWM on the WNPST on the interannual scale by taking into account the effects of local atmospheric baroclinicity (Lee et al. 2010; Zhang et al. 2014) and the width of the upper tropospheric jet (Harnik and Chang 2004). The present study emphasizes that the EAT can manipulate the WNPST through baroclinic energy conversion, which may provide a new perspective for studying the interaction between the EAWM and WNPST. In addition, the WNPST tends to relax the steep temperature gradient and demolish the local atmospheric baroclinicity by transporting sensible heat to the middle and high latitudes through its thermal forcing (Blackmon et al. 1977; Lau and Holopainen 1984; Straus and Shukla 1997; Nakamura et al. 2002), which leads to a tendency of self-annihilation. Although the storm track is affected by many factors and its maintenance mechanism is quite complicated, Nakamura et al. (2008) underlined the importance of the "oceanic baroclinic adjustment" process in preserving atmospheric baroclinicity and further maintaining the WNPST. Apart from the diabatic heating emphasized by Hoskins and Valdes (1990), Chang and Orlanski (1993) also believed that the maintenance of the WNPST is manipulated by the role of the "downstream development" mechanism. The present study shows that the WNPST may maintain itself through interactions with the EAT. For example, when the WNPST weakened, the impact of the WNPST, especially its dynamic forcing, on the geopotential height field attenuates the strength of the EAT, thereby abating the weakening effect of the EAT on the strength of WNPST, which is of positive significance for the development and maintenance of the WNPST.

Moreover, by carrying out empirical orthogonal function analysis on the geopotential height field of the EAT, Wang et al. (2009) well documented that in addition to the first leading mode featuring the strength of the EAT, the second leading mode presents the tilt of the EAT axis. The present study focuses only on the strength of the EAT, and whether the tilt of the EAT axis can affect the WNPST remains to be further studied. Furthermore, our preliminary study finds that El Niño-Southern Oscillation may modulate the correlation between the WNPST and EAT, which is the key issue we will focus on next.

Acknowledgements This research was joint supported by National Natural Science Foundation of China (grant nos. 41490642, 4160501 and 41520104008) and "Double First-Class" construction guidance project of National University of Defense Technology (project no. ZXBJGB02). The authors would like to thank two anonymous reviewers for their crucial comments. The first author thanks senior professor Lifeng Zhang for the useful discussion and her constructive comments in the class "atmospheric dynamics and numerical simulation".

Open Access This article is licensed under a Creative Commons Attribution 4.0 International License, which permits use, sharing, adaptation, distribution and reproduction in any medium or format, as long as you give appropriate credit to the original author(s) and the source, provide a link to the Creative Commons licence, and indicate if changes were made. The images or other third party material in this article are included in the article's Creative Commons licence, unless indicated otherwise in a credit line to the material. If material is not included in the article's Creative Commons licence and your intended use is not permitted by statutory regulation or exceeds the permitted use, you will need to obtain permission directly from the copyright holder. To view a copy of this licence, visit http://creativecommons.org/licenses/by/4.0/.

\section{References}

Blackmon ML (1976) A climatological spectral study of the $500 \mathrm{mb}$ geopotential height of the Northern Hemisphere. J Atmos Sci 33:1607-1623

Blackmon ML, Wallace JM, Lau NC (1977) An observation study of the Northern Hemisphere wintertime circulation. J Atmos Sci 34:1040-1053

Bozkurt D, Ezber Y, Sen OL (2019) Role of the East Asian trough on the eastern Mediterranean temperature variability in early spring and the extreme case of 2004 warm spell. Clim Dyn 53:2309-2326

Cai M, Yang S, Dool HMVD, Kousky VE (2007) Dynamical implications of the orientation of atmospheric eddies: a local energetics perspective. Tellus Ser A Dyn Meteorol Oceanol 59:127-140

Chang EKM, Fu Y (2002) Interdecadal variations in Northern Hemisphere winter storm track intensity. J Clim 15:642-658

Chang EKM, Orlanski I (1993) On the dynamics of a storm track. J Atmos Sci 50:999-1015 
Chang EKM, Lee S, Swanson KL (2002) Storm track dynamics. J Clim 15:2163-2183

Chang EKM, Guo Y, Xia XJ (2012) CMIP5 multimodel ensemble projection of storm track change under global warming. J Geophys Res. https://doi.org/10.1029/2012JD018578

Chen W, Yang S, Huang RH (2005) Relationship between stationary planetary wave activity and the East Asian winter monsoon. J Geophys Res. https://doi.org/10.1029/2004JD005669

Dee D, Uppala S, Simmons A, Berrisford P, Poli P, Kobayashi S, Andrae U, Balmaseda M, Balsamo G, Bauer P, Bechtold P, Beljaars A, van de Berg L, Bidlot J, Bormann N, Delsol C, Dragani R, Fuentes M, Geer A, Haimberger L, Healy S, Hersbach H, Hólm E, Isaksen L, Kållberg P, Köhler M, Matricardi M, Mcnally A, Monge-Sanz B, Morcrette J, Park B, Peubey C, de Rosnay P, Tavolato C, Thépaut J, Vitart F (2011) The ERA-Interim reanalysis: configuration and performance of the data assimilation system. Q J R Meteorol Soc 137:553-597

Ding Y, Liu Y, Liang S, Ma X, Zhang Y, Si D, Liang P, Song Y, Zhang J (2014) Interdecadal variability of the East Asian winter monsoon and its possible links to global climate change. J Meteorol Res 28:693-713

Dole RM, Black RX (1990) Life cycles of persistent anomalies. II: the development of persistent negative height anomalies over the North Pacific Ocean. Mon Weather Rev 118:824-846

Feng G, Zou M, Qiao S, Zhi R, Gong Z (1980s) The changing relationship between the December North Atlantic Oscillation and the following February East Asian trough before and after the late 1980s. Clim Dyn 51:4229-4242

Harnik N, Chang EKM (2004) The effects of variations in jet width on the growth of baroclinic waves: implications for midwinter pacific storm track variability. J Atmos Sci 61:23-40

Held IM, Ting M, Wang H (2002) Northern winter stationary waves: theory and modeling. J Clim 15:2125-2144

Hoskins BJ, Valdes PJ (1990) On the existence of storm-tracks. J Atmos Sci 47:1854-1864

Hoskins BJ, James IN, White GH (1983) The shape, propagation and mean-flow interaction of large-scale weather systems. J Atmos Sci 40:1595-1612

Hu F, Wang L, Zuo R, Xu R, Wang C (2018) Characteristics of the zonal sea surface temperature perturbation and its role in representing the evolution of the Kuroshio Extension. Clim Environ Res 23:551-562 (in Chinese)

Huang R, Chen J, Wang L, Lin Z (2012) Characteristics, processes, and causes of the spatio-temporal variabilities of the East Asian monsoon system. Adv Atmos Sci 29:910-942

Jhun J, Lee E (2004) A New East Asian Winter Monsoon Index and associated characteristics of the winter monsoon. J Clim 17:711-726

Jin F (2010) Eddy-induced instability for low-frequency variability. J Atmos Sci 67:1947-1964

Kug JS, Jin FF, Park J, Ren HL, Kang IS (2010) A general rule for synoptic-eddy feedback onto low-frequency flow. Clim Dyn 35:1011-1026

Lau NC (1988) Variability of the observed midlatitude storm tracks in relation to low-frequency changes in the circulation pattern. J Atmos Sci 45:2718-2743

Lau N, Holopainen E (1984) Transient eddy forcing of the timemean flow as identified by geopotential tendencies. J Atmos Sci 41:313-328

Lau N, Lau K (1984) The structure and energetics of midlatitude disturbances accompanying cold-air outbreaks over East Asia. Mon Weather Rev 112:1309-1327

Lau NC, Nath MJ (1991) Variability of the baroclinic and barotropic transient eddy forcing associated with monthly changes in the midlatitude storm tracks. J Atmos Sci 48:2589-2613
Lee Y, Lim G, Kug J (2010) Influence of the East Asian winter monsoon on the storm track activity over the North Pacific. J Geophys Res 115:156-157

Lee S, Lee J, Wang B, Jin F, Lee W, Ha K (2011) A comparison of climatological subseasonal variations in the wintertime storm track activity between the North Pacific and Atlantic: local energetics and moisture effect. Clim Dyn 37:2455-2469

Lee SS, Lee JY, Wang B, Ha KJ, Heo KY, Jin FF, Straus DM, Shukla J (2012) Interdecadal changes in the storm track activity over the North Pacific and North Atlantic. Clim Dyn 39:313-327

Lee S, Kim S, Jhun J, Ha K, Seo Y (2013) Robust warming over East Asia during the boreal winter monsoon and its possible causes. Environ Res Lett 8:034001

Leung MYT, Zhou W (2016) Eddy contributions at multiple timescales to the evolution of persistent anomalous East Asian trough. Clim Dyn 46:2287-2303

Leung MYT, Cheung HHN, Zhou W (2017) Meridional displacement of the East Asian trough and its response to the ENSO forcing. Clim Dyn 48:335-352

Li Y, Lau NC (2012) Contributions of downstream eddy development to the teleconnection between ENSO and the atmospheric circulation over the North Atlantic. J Clim 25:4993-5010

Li Y, Zhu W (2010) Reappraisal and improvement of winter storm track indices in the North Pacific. Chin J Atmos Sci 34:10011010 (in Chinese)

Liu C, Ren X, Yang X (2014) Mean flow-storm track relationship and Rossby wave breaking in two types of El Nino. Adv Atmos Sci 31:197-210

Luo D, Diao Y, Feldstein SB (2011) The variability of the Atlantic Storm Track and the North Atlantic Oscillation: a link between intraseasonal and interannual variability. J Atmos Sci 68:577-601

Ma X, Chang P, Saravanan R, Montuoro R, Nakamura H, Wu D, Lin X, Wu L (2017) Importance of resolving Kuroshio Front and Eddy influence in simulating the North Pacific Storm Track. J Clim 30:1861-1880

Miao J, Wang T, Wang H, Zhu Y, Sun J (2018) Interdecadal weakening of the East Asian Winter Monsoon in the mid-1980s: the roles of external forcings. J Clim 31:8985-9000

Nakamura H, Lin G, Yamagata T (1997) Decadal climate variability in the North Pacific during the recent decades. Bull Am Meteorol Soc 78:2215-2226

Nakamura H, Izumi T, Sampe T (2002) Interannual and decadal modulations recently observed in the Pacific storm track activity and East Asian winter monsoon. J Clim 15:1855-1874

Nakamura H, Sampe T, Goto A, Ohfuchi W, Xie S-P (2008) On the importance of midlatitude oceanic frontal zones for the mean state and dominant variability in the tropospheric circulation. Geophys Res Lett 35:15709

Ren XJ, Yang XQ, Han B, Xu GY (2007) North pacific storm track variations in winter season and the coupled pattern with the midlatitude atmosphere-ocean system. Chin J Geophys 50(1):94-103

Ren X, Zhang Y, Xiang Y (2008) Connections between wintertime jet stream variability, oceanic surface heating, and transient eddy activity in the North Pacific. J Geophys Res Atmos. https ://doi.org/10.1029/2007JD009464

Robertson AW, Metz W (1989) Three-dimensional linear instability of persistent anomalous large-scale flows. J Atmos Sci 46:2783-2801

Sen OL, Ezber Y, Bozkurt D (2019) Euro-Mediterranean climate variability in boreal winter: a potential role of the East Asian trough. Clim Dyn 52:7071-7084

Song L, Wang L, Chen W, Zhang Y (2016) Intraseasonal variation of the strength of the East Asian trough and its climatic impacts in boreal winter. J Clim 29:2557-2577 
Straus DM, Shukla J (1997) Variations of midlatitude transient dynamics associated with ENSO. J Atmos Sci 54:777-790

Sun B, Li C (1997) Relationship between the disturbances of East Asian trough and tropical convective activities in boreal winter. Chin Sci Bull 42:500-503 (in Chinese)

Wang H, He S (2012) Weakening relationship between East Asian winter monsoon and ENSO after mid-1970s. Chin Sci Bull $57: 3535-3540$

Wang L, Chen W, Zhou W, Huang R (2009) Interannual variations of East Asian trough axis at $500 \mathrm{hPa}$ and its association with the East Asian winter monsoon pathway. J Clim 22:600-614

Wang J, Kim H-M, Chang EKM (2017) Changes in Northern Hemisphere winter storm tracks under the background of Arctic amplification. J Clim 30:3705-3724

Wu Z, Li J, Jiang Z, He J (2011) Predictable climate dynamics of abnormal East Asian winter monsoon: once-in-a-century snowstorms in 2007/2008 winter. Clim Dyn 37:1661-1669
Yang S, Lau KM, Kim KM (2002) Variations of the East Asian jet stream and Asian-Pacific-American winter climate anomalies. J Clim 15:306-325

Yang M, Li X, Zuo R, Chen X, Wang L (2018) Climatology and interannual variability of winter North Pacific Storm Track in CMIP5 models. Atmosphere 9:79

Yang M, Tan Y, Li X, Chen X, Zhang C, Yu P (2020) Influence of cumulus convection schemes on winter North Pacific storm tracks in the regional climate model RegCM4.5. Int J Climatol 40:1294-1305. https://doi.org/10.1002/joc.6273

Zhang M, Qi Y, Hu X (2014) Impact of East Asian winter monsoon on the Pacific storm track. Meteorol Appl 21:873-878

Publisher's Note Springer Nature remains neutral with regard to jurisdictional claims in published maps and institutional affiliations. 